\title{
One-Pot Production of Substituted Anthraquinones via the Diene Synthesis in the Presence of Mo-V-P Heteropoly Acid Solutions
}

\author{
Leonid Gogin*, Elena Zhizhina \\ Boreskov Institute of Catalysis, Novosibirsk, Russia \\ Email: "gogin@catalysis.ru
}

Received 14 January 2014; revised 14 February 2014; accepted 20 February 2014

Copyright (C) 2014 by authors and Scientific Research Publishing Inc.

This work is licensed under the Creative Commons Attribution International License (CC BY). http://creativecommons.org/licenses/by/4.0/

\begin{abstract}
Acid-catalytic 1,3-butadiene condensation with para-quinones followed by the obtained product oxidation may be performed in one stage as one-pot process, if assisted by the aqueous solutions of Mo-V-P heteropoly acids with a composition of $\mathrm{H}_{\mathrm{a}} \mathrm{P}_{\mathrm{z}} \mathrm{Mo}_{\mathrm{y}} \mathrm{V}_{\mathrm{x}} \mathrm{O}_{\mathrm{b}}$. 1,4-naphthoquinone (NQ) condensation with 1,3-butadiene in HPA solutions (brutto-composition $\mathrm{H}_{15} \mathrm{P}_{4} \mathrm{Mo}_{18} \mathrm{~V}_{7} \mathrm{O}_{89}$ and $\mathrm{H}_{17} \mathrm{P}_{3} \mathrm{Mo}_{16} \mathrm{~V}_{10} \mathrm{O}_{89}$ ) in the presence of hydrophylic organic solvents (acetone, 1,4-dioxane) provides $70 \%$ yield of 9,10-anthraquinone (AQ) containing no less than $90 \% \mathrm{AQ}$. In the same conditions reaction NQ with substituted 1,3-butadienes in the presence of the aqueous $\mathrm{H}_{17} \mathrm{P}_{3} \mathrm{Mo}_{16} \mathrm{~V}_{10} \mathbf{O}_{89}$ (HPA-10) solution allows to prepare substituted $A Q$ with yield up to $90 \%$ and purity up to $99 \%$. The catalysts are regenerated by oxygen in separate stage and are reused.
\end{abstract}

\section{Keywords}

Substituted 9,10-Anthraquinones; Diene Synthesis; Mo-V-P Heteropoly Acids; Bifunctional Catalysts

\section{Introduction}

9,10-Anthraquinone (AQ) and its derivatives are the well known organic products [1]-[3]. They are used in production of dyes [2], hydrogen peroxide [3], medicals [3]. They are also applied as wood delignification catalysts [3]. Diene synthesis is known as a process for anthraquinones production. In case of substituted anthraquinones

\footnotetext{
${ }^{*}$ Corresponding author.
}

How to cite this paper: Gogin, L. and Zhizhina, E. (2014) One-Pot Production of Substituted Anthraquinones via the Diene Synthesis in the Presence of Mo-V-P Heteropoly Acid Solutions. Modern Research in Catalysis, 3, 57-61. 
this process is based on reaction between 1,4-naphthoquinone (NQ) and substituted 1,3-butadienes [1] [3]. It is also possible to use naphthoquinones with the same substitutes in positions 6,7 and (or) 5, 8. Primary addition products (adducts) are obtained in organic solvents (AQ synthesis is preformed under 1,3-butadiene pressure of

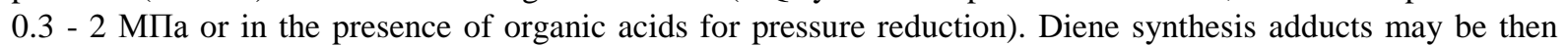
oxidized to AQ in acidic medium by strong oxidants $\left(\mathrm{CuCl}_{2}, \mathrm{H}_{2} \mathrm{O}_{2}\right.$ or $\mathrm{NaClO}_{3}$ [4]) or by air oxygen in alkaline medium [5]. In the latter case the process is rather slow. Thus 24 hours are required to transform the adduct of NQ reaction with 2,3-dimethylbutadiene into the corresponding AQ in 5\% alcohol solution of potassium hydroxide at room temperature under atmospheric pressure [6].

We have already developed [8]-[11] a one-pot process for the synthesis of non substituted 9,10-anthraquinone from NQ and 1,3-butadiene in the presence of high vanadium modified heteropoly acids solutions (HPA) of non-Keggin brutto composition $\mathrm{H}_{15} \mathrm{P}_{4} \mathrm{Mo}_{18} \mathrm{~V}_{7} \mathrm{O}_{89}$ (HPA-7) and $\mathrm{H}_{17} \mathrm{P}_{3} \mathrm{Mo}_{16} \mathrm{~V}_{10} \mathrm{O}_{89}$ (HPA-10), allowing a 70\% AQ yield, main substance content attaining $97 \%$. This process is performed in the butadiene atmosphere at $80^{\circ} \mathrm{C}$, molar ratio HPA:NQ being 2:1. Mixing with water organic solvents (acetone and 1,4-dioxane) is used for the purpose, their molar ratio to the aqueous HPA solution being 1:2. Being simultaneously strong Brøensted acids and oxidants, HPA solutions act as bi-functional catalysts, i.e. acid catalysts for the diene synthesis and oxidation catalysts for the adducts synthesis.

In the present study, we have used the above described method to obtain the substituted 9,10-anthraquinones in the presence of Mo-V-P HPA solutions.

\section{Experimental}

In all studies, we used 1,4-naphthoquinones, isoprene, 1-methyl- and 2,3-dimethylbutadienes Alfa Aesar. Chloroprene (2-chlorobutadiene) was prepared according to known method [12] by dehydrochlorination of 3,4dichlorobutene-1 with $20 \% \mathrm{NaOH}$ solution.

$0.2 \mathrm{M}$ solution HPA-10 (brutto-composition $\mathrm{H}_{17} \mathrm{P}_{3} \mathrm{Mo}_{16} \mathrm{~V}_{10} \mathrm{O}_{89}$ ) was prepared according to method described in [13]. The ${ }^{51} \mathrm{~V}$ and ${ }^{31} \mathrm{P}$ NMR spectra of the HPA-10 solution was recorded on the Bruker AVANCE 400 spectrometer at $105.24 \mathrm{MHz}$ and $162.0 \mathrm{MHz}$, respectively, with $85 \% \mathrm{H}_{3} \mathrm{PO}_{4}$ and $\mathrm{VOCl}_{3}$ as external standards.

The ${ }^{51} \mathrm{~V}$ and ${ }^{31} \mathrm{P}$ NMR spectra of the HPA-10 solution contains groups of lines typical of Keggin-type anions $\mathrm{H}_{x-1} \mathrm{PV}_{x} \mathrm{Mo}_{12-x} \mathrm{O}_{40}^{4-}$ (HPAn- $x, x=1-5$ ) [13]. In addition, the ${ }^{31} \mathrm{P}$ NMR spectrum shows a separate peak of $\mathrm{H}_{3} \mathrm{PO}_{4}$. Besides, there is a broad signal of cation $\mathrm{VO}_{2}^{+}$at $530-560$ ppm overlapping HPAn- $x$ lines in the ${ }^{51} \mathrm{~V}$ NMR spectrum (in more detail see [13] [14].

The atomic $\mathrm{P}:(\mathrm{Mo}+\mathrm{V})$ ratio is higher than $1 / 12$ in this non-Keggin HPA-10 solution. Therefore, it contains extra $\mathrm{H}_{3} \mathrm{PO}_{4}$, and the HPA-10 solution is actually a mixture of $\mathrm{H}_{3} \mathrm{PO}_{4}$ with different Keggin-type acids. But only for short we write the composition of the HPA-10 solutions as $\mathrm{H}_{17} \mathrm{P}_{3} \mathrm{Mo}_{16} \mathrm{~V}_{10} \mathrm{O}_{89}$.

Thermal stability of the HPA-10 solution was studied by running some cycles of reduction of $\mathrm{V}(\mathrm{V})$ to $\mathrm{V}(\mathrm{IV})$ by $10 \mathrm{M} \mathrm{N}_{2} \mathrm{H}_{4} \cdot \mathrm{H}_{2} \mathrm{O}$ at $100^{\circ} \mathrm{C}$ [15] followed by its regeneration with $\mathrm{O}_{2}$ at different temperatures and $\mathrm{PO}_{2}=4$ at (405 kPa). The results of many-cycled tests shown that $0.2 \mathrm{M} \mathrm{HPA}-10$ solution are stable up to $170^{\circ} \mathrm{C}$. It means that it can be successfully regenerated at $150^{\circ} \mathrm{C}-170^{\circ} \mathrm{C}$ with retaining its homogeneity. This solution is quite promising as a bifunctional catalyst.

HPLC method was applied for reaction product analysis. For the purpose we used liquid chromatograph Pro-Star equipped with UV-detector (wavelength $247 \mathrm{~nm}$ ). Separation was done on column Pursuit 3 C18, $247 \times$ $4.6 \mathrm{~mm}$, eluting reagent flow rate being $1 \mathrm{ml} / \mathrm{min}$. We used commercial available solvents for the chromatography without further purification. Eluting composition was $70 \% \mathrm{CH}_{3} \mathrm{OH}+30 \% \mathrm{CF}_{3} \mathrm{COOH}$, sample solvent $\mathrm{CHCl}_{3}$.

All substituted AQ were identified by chromatography-mass spectrometry and comparison their HPLC retention times with commercial samples.

Substituted AQ were synthesized in a thermostat glass reactor by introducing substrate (NQ or 6,7-dimethyl-NQ) in amount of $0.2 \mathrm{~g}$. Then $8 \mathrm{ml}$ of organic solvent were added under stirring. After substrate dissolving, $0.2 \mathrm{M}$ aqueous solution of HPA-10 $\left(\mathrm{H}_{17} \mathrm{P}_{3} \mathrm{Mo}_{16} \mathrm{~V}_{10} \mathrm{O}_{89}\right)$ and diene were added in required amount. After that reactor jacket was connected to thermostat preliminary heated to $80^{\circ} \mathrm{C}$. Reaction mixture was vigorously mixed with magnetic stirrer $\left(650 \mathrm{~min}^{-1}\right)$ for 7 hours. In the synthesis course HPA changed its color from dark red to green, while reaction product precipitated.

After process completion reaction mixture was twice diluted by water, solid precipitate was filtered away, 
washed with water to neutral $\mathrm{pH}$ and dried in vacuum over $\mathrm{P}_{2} \mathrm{O}_{5}$. After drying precipitate was weighted and analyzed with HPLC.

The substituted AQ yield was calculated according to the formula:

$$
\mathrm{Y}_{\mathrm{AQ}}=\left(\mathrm{M} \times \mathrm{C}_{\mathrm{AQ}} \times 100\right) / \mathrm{g}
$$

where $\mathrm{M}$ is the dry product mass, $\mathrm{g}$; $\mathrm{C}_{\mathrm{AQ}}$ is the substituted $\mathrm{AQ}$ portion in precipitate according to analysis; $\mathrm{g}$ - the theoretically possible value of substituted AQ mass (for full NQ conversion into AQ), g.

After solvent and water access were distilled away (dioxane azeotrope with water boiled at $88^{\circ} \mathrm{C}$ ), reduced HPA-10 was regenerated by oxygen according to procedure described elsewhere [16] and many timed reused. No catalyst regeneration was performed, when diglyme was used as solvent $\left(\mathrm{t}_{\mathrm{b}}=162^{\circ} \mathrm{C}\right)$.

\section{Results and Discussion}

In the present work, we have synthesized substituted anthraquinones in the presence of aqueous HPA-10 solution according to scheme:<smiles>[R]C=C([R])C([R3])=C[R16]([H])([H])C(C)C</smiles>

Synthesis conditions and experimental results are given in Table 1.

NQ reaction with methylsubstituted butadienes-isoprene (2-methylbutadiene) and trans-piperylene (trans-1methylbutadiene)—yields corresponding methylanthraquinones under conditions described elsewhere [11]. In case of trans-piperylene reaction goes easily with a rather high yield (84\%) giving 99\% pure 1-methylanthraquinones. As for isoprene dissolved in dioxane, reaction produces a rather pure corresponding anthraquinone (98\%), but its yield is not high (50\%).

NQ and 6,7-dimethyl-NQ interaction with 2,3-dimethylbutadiene proceeds smoothly, giving 2,3-dimethylanthraquinone and 2,3,6,7-tetramethylanthraquinone with yields $78 \%$ and $70 \%$, respectively. The worst results are related to chloroprene (2-chlorobutadiene), since chloroanthraquinone yield does not exceed 30\%.

In order to increase the yield of desired products we have varied the conditions for the synthesis of 2-methyland 2-chloroanthraquinones (see Table 2). Apparently, within the tried reaction conditions we have failed to increase the yield of 2-chloroanthraquinone.

However, in case of 2-methylanthraquinone dioxane substitution by diglyme allows to increase the product yield up to $80 \%$ (Table 2). Note also that as molar ratio HPA-10: NQ decreases from 2:1 to 0.5:1 (theoretically ratio 0.4:1 is enough for the complete diene synthesis adduct oxidation to AQ) 2-methylanthraquinone yield increases but not decreases. Similar result we observe for 1-methylanthraquinone. Most likely this is caused by the less product loss due to the side oxidation processes occurring in the excess of HPA, which is a rather strong oxidant with solution redox potential of about $1.0 \mathrm{~V}$ [17]. Therefore one may essentially reduce catalyst weight in case of substituted AQ, thus using molar ratio substrate: HPA lower than 2:1. This should allow the higher efficiency of developed one-pot processes for the synthesis of substituted AQ.

\section{Conclusions}

The one-pot synthesis of substituted 9,10-anthraquinones by reactions of 1,4-naphthaquinone and 6,7-dimethyl1,4-naphthaquinone with substituted 1,3-butadienes in the presence of aqueous HPA-10 solutions mixed with organic solvents has been developed. This method is proved to produce substituted anthraquinones with the $90 \%$ yield and $96 \%$ - 97\% purity.

The obtained results open perspective for the low waste single stage processes for substituted AQ production 
Table 1. Experimental results related to the diene synthesis of substituted anthraquinones.

\begin{tabular}{ccc}
\hline Substituent & Yield of substituted AQ, \% & AQ content in product, \% \\
\hline $\mathrm{R}_{1}=\mathrm{R}_{2}=\mathrm{R}_{3}=\mathrm{R}_{5}=\mathrm{R}_{6}=\mathrm{H}$ & 69.7 & 97 \\
$\mathrm{R}_{1}=\mathrm{R}_{3}=\mathrm{R}_{5}=\mathrm{R}_{6}=\mathrm{H}$ & 50 & 98 \\
$\mathrm{R}_{2}=\mathrm{CH}_{3}$ & & \\
$\mathrm{R}_{2}=\mathrm{R}_{3}=\mathrm{R}_{5}=\mathrm{R}_{6}=\mathrm{H}$ & 84 & 99 \\
$\mathrm{R}_{1}=\mathrm{CH}_{3}$ & 78 & 98 \\
$\mathrm{R}_{1}=\mathrm{R}_{5}=\mathrm{R}_{6}=\mathrm{H}$ & & \\
$\mathrm{R}_{2}=\mathrm{R}_{3}=\mathrm{CH}_{3}$ & 30 & 95 \\
$\mathrm{R}_{1}=\mathrm{R}_{3}=\mathrm{R}_{5}=\mathrm{R}_{6}=\mathrm{H}$ & & \\
$\mathrm{R}_{2}=\mathrm{Cl}$ & & 94 \\
$\mathrm{R}_{2}=\mathrm{R}_{3}=\mathrm{R}_{5}=\mathrm{R}_{6}=\mathrm{CH}_{3}$ & 70 & 94 \\
$\mathrm{R}_{1}=\mathrm{H}$ & &
\end{tabular}

Reaction conditions: $15.6 \mathrm{ml}$ of $0.2 \mathrm{M}$ aqueous solution of HPA-10, molar ratio HPA-10/NQ = 2, organic solvent (1,4-dioxane) volume $8 \mathrm{ml}$, reaction time $7 \mathrm{~h}$, temperature $80^{\circ} \mathrm{C}$.

Table 2. Reaction parameters influence on the yield and purity of substituted methylanthraquinones.

\begin{tabular}{|c|c|c|c|c|c|}
\hline Substituent & Solvent & $\begin{array}{l}\text { Volume of HPA } \\
\text { solution, ml }\end{array}$ & $\begin{array}{c}\text { Molar ratio } \\
\text { HPA-10/NQ }\end{array}$ & $\begin{array}{c}\text { Yield of AQ, } \\
\%\end{array}$ & $\begin{array}{c}\text { AQ content in } \\
\text { product, \% }\end{array}$ \\
\hline $\mathrm{R}_{1}=\mathrm{R}_{3}=\mathrm{R}_{5}=\mathrm{R}_{6}=\mathrm{H} \mathrm{R}_{2}=\mathrm{CH}_{3}$ & Diglyme & 15.6 & 2 & 80 & 96 \\
\hline $\mathrm{R}_{1}=\mathrm{R}_{3}=\mathrm{R}_{5}=\mathrm{R}_{6}=\mathrm{H} \mathrm{R}_{2}=\mathrm{CH}_{3}$ & 1,4-Dioxane & 7.8 & 1 & 71 & 97 \\
\hline $\mathrm{R}_{1}=\mathrm{R}_{3}=\mathrm{R}_{5}=\mathrm{R}_{6}=\mathrm{H} \mathrm{R}_{2}=\mathrm{CH}_{3}$ & 1,4-Dioxane & 5.9 & 0,75 & 70 & 96 \\
\hline $\mathrm{R}_{1}=\mathrm{R}_{3}=\mathrm{R}_{5}=\mathrm{R}_{6}=\mathrm{H} \mathrm{R}_{2}=\mathrm{CH}_{3}$ & 1,4-Dioxane & 3.9 & 0,5 & 72 & 96 \\
\hline $\mathrm{R}_{1}=\mathrm{R}_{3}=\mathrm{R}_{5}=\mathrm{R}_{6}=\mathrm{H} \mathrm{R}_{1}=\mathrm{CH}_{3}$ & 1,4-Dioxane & 7.8 & 1 & 91 & 99 \\
\hline $\begin{array}{c}\mathrm{R}_{1}=\mathrm{R}_{3}=\mathrm{R}_{5}=\mathrm{R}_{6}=\mathrm{H} \\
\mathrm{R}_{2}=\mathrm{Cl}\end{array}$ & 1,4-Dioxane & 15.6 & 2 & 25 & 97 \\
\hline $\begin{array}{c}\mathrm{R}_{1}=\mathrm{R}_{3}=\mathrm{R}_{5}=\mathrm{R}_{6}=\mathrm{H} \\
\mathrm{R}_{2}=\mathrm{Cl}\end{array}$ & $\begin{array}{l}\text { 1,4-Dioxane: } \\
\text { ethanol 1:1 }\end{array}$ & 15.6 & 2 & 18 & 97 \\
\hline
\end{tabular}

Reaction conditions: 0.2 g NQ, $0.2 \mathrm{M}$ aqueous solution of HPA-10, organic solvent volume $8 \mathrm{ml}$, reaction time $7 \mathrm{~h}$, temperature $80^{\circ} \mathrm{C}$.

from substituted 1,3-butadienes and NQ in the presence of Mo-V-P HPA solutions being bi-functional (acid and oxidation) catalysts.

\section{References}

[1] Gorelik, M.V. (1983) Chemistry of Anthraquinones and Their Derivatives. Khimia, Moscow.

[2] (2005) Anthraquinone Dyes and Intermediates. In: Ullmann's Encyclopedia of Industrial Chemistry, Wiley-VCH Verlag GmbH \& Co. KGaA, Weinheim.

[3] (2006) Anthraquinone. In: Kirk-Othmer Encyclopedia of Chemical Technology, 5th Edition, John Wiley \& Sons, New York, 419-427.

[4] Ju, H.S., Ju, Y.J., Kim, J.E. and Won, J.I. (2001) Preparation of Napthoquinone and Anthraquinone Using Oxidizing Agent. KR Patent No. 2001004856.

[5] Ju, H.S., Ju, Y.J., Kim, J.E. and Won, J.I. (2000) Method of Manufacturing Anthraquinone from 1,4-Napthoquinone and 1,3-Butadiene. KR Patent No. 2000001821.

[6] (1942) Organic Syntheses. John Wiley \& Sons, New-York.

[7] Kozhevnikov, I.V. (1998) Catalysis by Heteropoly Acids and Multicomponent Polyoxometal-lates in Liquid-Phase Reactions. Chemical Reviews, 98, 171-198. http://dx.doi.org/10.1021/cr960400y

[8] Zhizhina, E.G., Matveev, K.I. and Russkikh, V.V. (2004) 1,4-Naphto- and 9,10-Anthraquinone Catalytic Preparation by Diene Synthesis Reaction for Cellulose-Paper Industry. Khimiya v Interesakh Ustoichivogo Razvitiya, 12, 47-51.

[9] Zhizhina, E.G., Simonova, M.V., Odyakov, V.F. and Matveev, K.I. (2005) Catalytic Synthesis of 9,10-Anthraquinone in the Presence of Mo-V-Phosphoric Heteropoly Acids Solutions. Catalysis in Industry, 12-17. 
[10] Zhizhina, E.G. and Odyakov, V.F. (2012) Aqueous Solutions of Mo-V-P Heteropoly Acids as Bifunctional Catalysts for Preparation of 9,10-Anthraquinone and Its Hydrogenated Derivatives. ChemCatChem, 4, 1405-1410. http://dx.doi.org/10.1002/cctc.201200039

[11] Gogin, L.L., Zhizhina, E.G. and Pai, Z.P. (2013) Low-Waste One-Pot Process of Anthraquinone Production via Diene Synthesis in the Presence of Heteropoly Acids Solutions. Khimiya v Interesakh Ustoichivogo Razvitiya, 21, 123-127.

[12] Weygand-Hilgetag (1968) Methods of Experiment in Organic Chemistry. Khimia, Moscow.

[13] Odyakov, V.F., Zhizhina, E.G. and Maksimovskaya, R.I. (2008) Synthesis of Molybdovanadophos-Phoric Heteropoly Acid Solutions Having Modified Composition. Applied Catalysis A: General, 342, 126-130. http://dx.doi.org/10.1016/j.apcata.2008.03.008

[14] Selling, A., Andersson, I., Grate, J.H. and Pettersson, L. (2000) A Potentiometric and (31P, 51V) NMR Study of the Aqueous Molybdovanadophosphate System. European Journal of Inorganic Chemistry, 2000, 1509-1521.

[15] Zhizhina, E.G., Odyakov, V.F. and Matveev, K.I. (1999) Thermochemical Study of Reduction and Oxidation Reactions of Molybdovanadophosphoric Heteropoly Acids in Aqueous Solutions. European Journal of Inorganic Chemistry, 1999, 1009-1014.

[16] Zhizhina, E.G., Simonova, M.V., Odyakov, V.F. and Matveev, K.I. (2004) Regeneration of Catalysts Based on Aqueous Solutions of Mo-V-P Heteropoly Acids. Khimiya v Interesakh Ustoichivogo Razvitiya, 6, 683-688.

[17] Kozhevnikov, I.V. and Matveev, K.I. (1982) Heteropoly Acids in Catalysis. Russian Chemical Reviews, 51, 18751896. 